\title{
Evaluation of Lipoxin A4 as A Marker of Severity of Bronchial Asthma in Pediatrics in Zagazig University Hospital
}

\author{
Kossay Usama Mohamed ${ }^{1}$, Saad Ahmed Mansour ${ }^{1}$, Sanaa Mahmoud Abdelsalam², Seham Mahrous Zaki ${ }^{1}$ \\ Departments of ${ }^{1}$ Pediatrics and ${ }^{2}$ Clinical Pathology, Faculty of Medicine - Zagazig University \\ *Corresponding Author: Kossay Usama Mohamed, Mobile: (+20)01024683929, \\ Email: mosad8rashed@gmail.com
}

\begin{abstract}
Background: Asthma is a common, chronic respiratory disease affecting 1-18\% of the population in different countries. Lipoxins were the first agents to be identified as anti-inflammatory endogenous lipid mediators involved in the resolution of inflammation.

Objective: The study aimed to test this hypothesis via investigating the serum levels of lipoxin A4 in a group of pediatric patients comparing to controls. Also to examine potential differences in lipox in A4 levels in relation to the severity of asthma.

Patients and Methods: A case-control study was conducted at Zagazig University. Sample size was 22 children in cases group and 22 children in controls group. Twenty two patients were classified as mild, moderate and severe persistent asthma. All children were subjected to lipoxin levels assay.

Results: Serum lipoxin A4 levels were significantly higher in all asthmatic patients compared to controls group with $\mathrm{P}$ value $(<0.05)$. There was statistically significant difference between degree of severity and lipoxin level. On pairwise comparison, the difference was significant between mild and severe group $(\mathrm{P}=0.01)$. Our study shows that there was significant increase of serum LXA4 levels in patients with severe asthma compared to those with moderate and mild asthma.
\end{abstract}

Conclusion: Serum lipoxin was significantly elevated in asthma patients when compared to controls $(\mathrm{P}<0.05)$. Serum lipoxin levels in severe asthmatics were significantly higher than in moderate and mild asthmatics $(\mathrm{P}<0.01)$. Keywords: Lipoxin A4, Bronchial asthma, Severity of asthma.

\section{INTRODUCTION:}

Asthma is a common, chronic respiratory disease affecting $1-18 \%$ of the population in different countries. It is characterized by variable symptoms of wheeze, shortness of breath, chest tightness and/or cough, and by variable expiratory airflow limitation. Both symptoms and airflow limitation characteristically vary over time and in intensity. These variations are often triggered by factors such as exercise, allergen or irritant exposure, change in weather, or viral respiratory infections. Symptoms and airflow limitation may resolve spontaneously or in response to medication, and may sometimes be absent for weeks or months at a time ${ }^{(1)}$.

Lipoxins were the first agents to be identified as anti-inflammatory endogenous lipid mediators involved in the resolution of inflammation (2). The activation of inflammatory cascades is accompanied by the generation of pro-resolving mediators which restore tissue homeostasis by antagonism of inflammation and promotion of immune defense mechanisms. Among these moieties are lipoxinslipoxygenase interaction products of arachidonic acid metabolism ${ }^{(3)}$.

Lipoxin A4 (LXA4) suppresses air way hyperresponsiveness and pulmonary inflammation through anti-inflammatory receptors, namely ALX/FBR2 receptors, expressed on both leucocytes and air way epithelial cells ${ }^{(4)}$.
The study aimed to test this hypothesis via investigating the serum levels of lipoxin A4 in a group of pediatric patients with persistent asthma attack, comparing results to a matched healthy group of controls. The study also examined potential differences in lipox in A4 levels in relation to the severity of asthma.

\section{PATIENTS AND METHODS}

A case-control study was conducted at University Hospital, Faculty of Medicine, Zagazig University, Egypt. It was held from November 2017 to November 2018. Sample size was 22 children in cases group and 22 children in controls group. Candidates were recruited from the allergy and pulmonology clinic. Cases group:

Twenty-two patients were included in this group. They were classified as mild, moderate and severe persistent asthma (the cases were newly diagnosed before starting asthma control therapy) (diagnosis and classification of asthma according to GINA guidelines $2016^{(1)}$.

\section{Inclusion criteria:}

Age from 3-12 years. Cases with mild, moderate and severe persistent asthma. No associated chest infection or diseases causing respiratory distress other than asthma. No intake of systemic corticosteroids 2 weeks before study enrollment. Approval to participate in the study.

This article is an open access article distributed under the terms and conditions of the Creative Commons Attribution (CC BY-SA) license (http://creativecommons.org/licenses/by/4.0/) 


\section{Exclusion criteria:}

Cases with dehydration, malignancy, immunocompromized patients and coagulopathy. Cases with end-stage liver and renal disease. Children with wheezy chest due to causes other than asthma.

Control group: Twenty healthy children were included in this study. They were recruited from the follow-up and other clinics of the hospital. They were age- and sex-matched to the cases group.

\section{Ethical considerations:}

The aim and nature of the study was explained for each parent before inclusion. An informed verbal consent was obtained from parents/surrogates before enrollment. The study design conformed to the requirements of latest revision of Helsinki Declaration of Bioethics (2008). The Scientific Research Committee of Pediatrics DepartmentFaculty of Medicine, Zagazig University approved the study design.

\section{Clinical methods:}

All children were subjected to a complete clinical study (through history and physical examination) upon study inclusion, with emphasis on symptoms and signs for degree of asthma (classification of asthma severity according to GINA guide lines $\left.2016^{(1)}\right)$.

\section{Laboratory methods:}

The following investigations were performed:

A) Sample collection: Five $\mathrm{ml}$ of venous blood were withdrawn and collected into vacutainer tubes.

Two $\mathrm{ml}$ were added to EDTA containing vacutainers for the performance of CBC. Three $\mathrm{ml}$ were added to vacutainers containing no anticoagulant for the lipoxin assay. Blood was centrifuged at $1600 \mathrm{xg}$ for 15 minutes at 4 degrees Celsius and serum was collected and kept at -20 degrees Celsius till the assay was performed after all samples were collected from all patients and controls.

B) Complete blood count: CBC was done by Sysmex- 800 i.

\section{C) Lipoxin assay:}

Lipoxin levels assay by enzyme-linked immunosorbent assay (ELISA) method (2400 Veterans Blvd. Suite 16 - 101, Del Rio, TX 78840, Glory Science, USA).

\section{Principle of the test:}

The kit uses a double-antibody sandwich enzymelinked immunosorbent assay (ELISA) to assay the level of Human Lipoxin- A4 (LXA4) in samples. Lipoxin - A4 (LXA4) was added to monoclonal antibody enzyme well which was pre-coated with Human Lipoxin-A4 (LXA4) monoclonal antibody, incubation; then, Lipoxin - A4 (LXA4) antibodies labeled with biotin were added, and combined with streptavidin-HRP to form immune complex; then the incubation was carried out and washing again to remove the uncombined enzyme. Then chromogen solution A, B were added, the color of the liquid changes into the blue, and at the effect of acid, the color finally becomes yellow. The chroma of color and the concenthum anion of the Human Substance Lipoxin-A4 (LXA4) of sample were positively correlated.

\section{Steps:}

- All reagents, working standards, and samples were prepared.

- Prepared samples and standards, and standard, sample, or positive control were added to $100 \mu \mathrm{l}$ of LX Biotin reagent.

- The contents were swirled gently for 20-30 seconds.

- The contents were incubated at room temperature 20-24 degree Celsius for 60 minutes.

- The immunoplate was washed 5 times with $300 \mu \mathrm{l} /$ well of wash buffer.

- One hundred $\mu \mathrm{l} /$ well of the anti LX-HRP labeled antibody were added.

- The contents were incubated at 30 degree Celsius for 60 minutes.

- The immunoplate was washed 5 times $300 \mu \mathrm{l} /$ well of wash buffer.

- One hundred $\mu \mathrm{l} /$ well of the chromogen solution A, B were added.

- The contents were incubated at room temperature 20-24 degree Celsius for 10 minutes.

- The reaction was terminated with $50 \mu \mathrm{l} /$ well of two normal HCL.

\section{Statistical analysis}

Recorded data were analyzed using the statistical package for social sciences, version 20.0 (SPSS Inc., Chicago, Illinois, USA). Quantitative data were expressed as mean \pm standard deviation (SD).

Qualitative data were expressed as frequency and percentage. Independent-samples t-test of significance was used when comparing between two means. Chisquare $\left(\mathrm{x}^{2}\right)$ test of significance was used in order to compare proportions between two qualitative parameters. The confidence interval was set to $95 \%$ and the margin of error accepted was set to $5 \%$.

The p-value was considered significant as the following: P-value $<0.05$ was considered significant. $\mathrm{P}$-value $<0.001$ was considered as highly significant. Pvalue $>0.05$ was considered insignificant. 


\section{RESULTS}

There was no statistically significant difference between asthma and control group regarding age, gender or residence (Table 1).

Table (1): Demographic characteristics of studied groups.

\begin{tabular}{|l|c|c|c|c|}
\hline & Asthma group (22) & Control group (22) & MW & p \\
\hline $\begin{array}{l}\text { Age: } \\
\text { Mean } \pm \text { SD }\end{array}$ & $6.64 \pm 2.74$ & $6.64 \pm 2.16$ & -0.177 & 0.860 \\
\hline & & & $\mathbf{X}^{\mathbf{2}}$ & $\mathbf{p}$ \\
\hline $\begin{array}{l}\text { Gender: } \\
\text { Male }\end{array}$ & $11(50)$ & $\begin{array}{c}14(63.6) \\
8(36.4)\end{array}$ & 0.834 & 0.361 \\
Female & $11(50)$ & $12(54.5)$ & 0.091 & 0.763 \\
\hline $\begin{array}{l}\text { Residence: } \\
\text { Rural } \\
\text { Urban }\end{array}$ & $11(50)$ & $10(45.5)$ & & \\
\hline
\end{tabular}

MW: Mann-Whitney test

There was statistically significant difference regarding age of asthmatic patients according to severity. No statistically significant difference between the studied groups regarding gender or residence was found (Table 2).

Table (2): Demographic characteristics of studied groups according to severity of asthma.

\begin{tabular}{|c|c|c|c|c|c|}
\hline 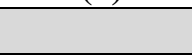 & Mild & Moderate & Severe & KW & $\mathbf{p}$ \\
\hline $\begin{array}{l}\text { Age: } \\
\text { Mean } \pm \text { SD }\end{array}$ & $6.25 \pm 2.74$ & $9.08 \pm 1.43^{¥}$ & $4.13 \pm 0.85$ & 8.717 & $0.013^{*}$ \\
\hline & & & & $X^{2}$ & \\
\hline $\begin{array}{l}\text { Gender: } \\
\text { Male } \\
\text { Female }\end{array}$ & $\begin{array}{l}5(41.7) \\
7(58.3) \\
\end{array}$ & $\begin{array}{l}2(33.3) \\
4(66.7) \\
\end{array}$ & $\begin{array}{c}4(100) \\
0(0)\end{array}$ & 5 & 0.082 \\
\hline $\begin{array}{l}\text { Residence: } \\
\text { Rural } \\
\text { Urban }\end{array}$ & $\begin{array}{l}6(50) \\
6(50)\end{array}$ & $\begin{array}{l}3(50) \\
3(50)\end{array}$ & $\begin{array}{l}2(50) \\
2(50)\end{array}$ & 0 & 1 \\
\hline
\end{tabular}

KW: Kruskal-Wallis test

*: $\mathrm{P}$ is significant

There was statistically significant difference between asthma and control groups regarding blood lipoxin A4 level (Table 3).

Table (3): Blood lipoxin value in studied groups.

\begin{tabular}{|l|c|c|c|c|}
\hline & Asthma group & Control group & MW & p \\
\hline $\begin{array}{l}\text { Lipoxin: } \\
\text { Mean } \pm \text { SD }\end{array}$ & $60.55 \pm 58.86$ & $23.78 \pm 37.52$ & -2.394 & $0.017 *$ \\
\hline \multicolumn{2}{|l|}{ *: P is significant } \\
\hline
\end{tabular}

There was statistically significant difference between degree of severity and lipoxin level. On pairwise comparison, the difference was significant between mild and severe group $(\mathrm{p}=0.001)$ (Table 4).

Table (4): Blood lipoxin value in studied groups according to severity of asthma.

\begin{tabular}{|c|c|c|c|c|c|}
\hline & Mild & Moderate & Severe & KW & p \\
\hline $\begin{array}{l}\text { Lipoxin: } \\
\text { Mean } \pm \text { SD }\end{array}$ & $\mathbf{2 2 . 4 3} \pm \mathbf{2 3 . 4}$ & $\mathbf{2 3 . 7 8} \pm \mathbf{3 7 . 5 2}$ & $\mathbf{1 6 4 . 5 8 8} \pm \mathbf{1 8 . 9}$ & $\mathbf{1 4 . 0 4 7}$ & $\mathbf{0 . 0 0 1} * *$ \\
\hline
\end{tabular}

The best cutoff value of blood lipoxin A4 level in diagnosis of asthma was $\geq 18.74$ (Table 5 and figure 1). 
Table (5): Performance of blood lipoxin A4 level in diagnosis of asthma.

\begin{tabular}{|l|c|c|c|c|c|c|c|c|c|}
\hline Cutoff & AUC & Sensitivity & Specificity & PPV & NPV & +LR & -LR & Accuracy & p \\
\hline$\geq 18.74$ & $\mathbf{0 . 7 1 1}$ & 63.6 & 63.6 & 63.6 & 63.6 & 9.0 & 0 & 63.6 & $0.017^{*}$ \\
\hline
\end{tabular}

*P is significant

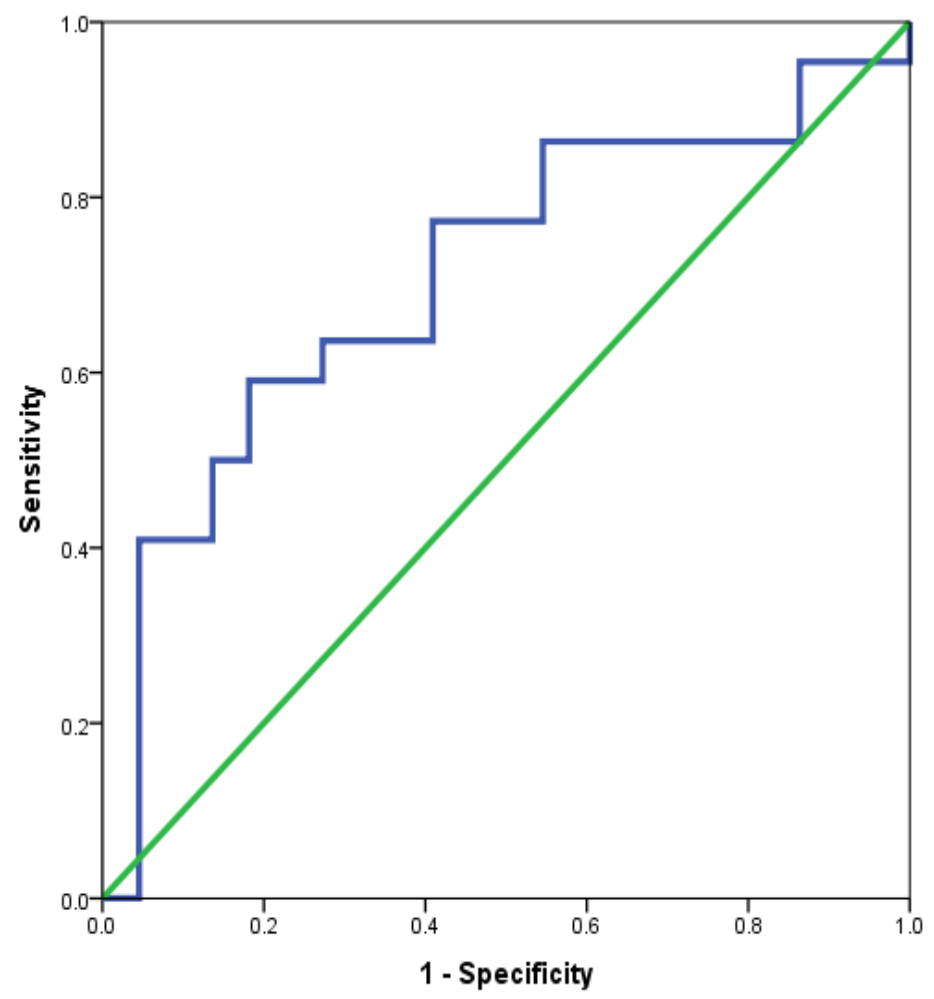

Figure (1): ROC curve showing performance of blood lipoxin A4 level in diagnosis of asthma.

The best cutoff value of blood lipoxin A4 level in diagnosis moderate asthma was $\geq 33.24$ (Table 6).

Table (6) Performance of blood lipoxin A4 level in diagnosis of moderate asthma.

\begin{tabular}{|l|l|l|l|l|l|l|l|l|c|}
\hline Cutoff & AUC & Sensitivity & Specificity & PPV & NPV & +LR & -LR & Accuracy & p \\
\hline$\geq 33.24$ & 0.902 & 100 & 79.4 & 100 & 46.2 & 4.85 & 0 & 82.5 & $0.002 *$ \\
\hline
\end{tabular}

**: $\mathrm{P}$ is highly significant

The best cutoff value of blood lipoxin A4 level in diagnosis of severe asthma was $\geq 90.329$ (Table 7).

Table (7) Performance of blood lipoxin A4 level in diagnosis of severe asthma.

\begin{tabular}{|l|c|c|c|c|c|c|c|c|c|}
\hline Cutoff & AUC & Sensitivity & Specificity & PPV & NPV & +LR & -LR & Accuracy & $p$ \\
\hline$\geq 90.329$ & 1 & 100 & 88.9 & 100 & 66.7 & 9.0 & 0 & 90.9 & $<0.001 * *$ \\
\hline
\end{tabular}

**: $\mathrm{P}$ is highly significant 


\section{DISCUSSION}

This study was done to detect lipoxin levels in asthmatic children. According to demographic data, our study revealed no statistically significant difference between asthma and control group regarding age, gender or residence.

This was in agreement with the study done by Nafti et al. ${ }^{(5)}$ on the prevalence of asthma in North Africa especially in Algeria where the prevalence rates in males and females were comparable.

Regarding lipoxin, our study revealed no significant difference between asthma and control groups regarding blood lipoxin A4.

Serum lipoxin A4 levels were significantly higher in all asthmatic patients compared to controls group.

Our result is in agreement with Simone et al. ${ }^{(6)}$ which stated that blood LXA4 in 106 patients with asthma were higher than those of controls.

There was statistically significant difference between degree of severity and lipoxin level. On pairwise comparison, the difference was significant between mild and severe group.

Our study showed that there was significant increase of serum LXA4 levels in patients with severe asthma compared to those with moderate and mild asthma .

Our result was against Levy et al. ${ }^{(7)}$ who stated that the expression of 15-LO in leukocytes and the levels of blood LXA4 were gradually decreased with severity degree of asthma, although all values were still higher than that of controls suggesting that diminished capacity for LXA4 formation by severe asthmatic children may contribute to their more severe clinical phenotype.

Our results were against the findings of Yin $\boldsymbol{e t}$ al. ${ }^{(8)}$ who studied asthmatic children with different grades of asthma severity. The authors found that the leukocyte 15-LO expression and blood LXA4 progressively decreased in children with asthma from mild degree to moderate and severe degree suggesting that insufficient generation of LXA may be related to a more severe illness in asthmatic children.

Similarly, Rabie et al. ${ }^{(9)}$, reported significantly higher plasma lipoxin levels in adults with mild asthma compared to normal subjects. Plasma lipoxin levels were also significantly higher in mild asthmatics in moderate disease $(\mathrm{P}=0.001)$ and were significantly higher in severe asthmatics than normal subjects ( $\mathrm{P}$ $=0.002$ ). Studies had also shown an imbalance between the generation of proinflammatory leukotrienes and counter-regulatory lipoxins generated by alveolar macrophages ${ }^{(10)}$. The study showed that LXA4 biosynthesis was decreased from severe asthma alveolar macrophages (AMs) compared to non-severe asthma $(\mathrm{p}<0.05)$ and normal subjects $(\mathrm{p}<0.001)$.
LXA4 induced by LPS was highest in normal subjects and lowest in severe asthmatics ( $\mathrm{p}<0.001)$.

Vachier et al. ${ }^{(11)}$ conducted a study measuring loss of LX4, an endogenous anti-inflammatory compound in severe asthmatic patients. Lipoxin level was assessed in induced sputum supernatants that were collected from 10 normal subjects; 12 subjects with mild, 15 with moderate, and 24 with severe asthma; in addition to 13 patients with chronic obstructive pulmonary disease. The study showed that lipoxin A4 was significantly increased in the supernatant obtained from patients with mild asthma than in the normal group $(\mathrm{P}<0.001)$

A study done by Levy et al. ${ }^{(12)}$ found that samples of activated whole blood from individuals with severe asthma generated significantly less LXA4 than did samples from subjects with moderate asthma. Similarly, by measuring LXA4 in supernatant of induced sputum, they showed that patients with mild asthma released higher LXA4 concentrations than patients with severe asthma and normal subjects. The authors concluded that among individuals with severe asthma, the persistent inflammation, airflow obstruction, and frequent symptoms may result from decrements in the levels of counter regulatory lipoxin molecules that help to prevent bronchoconstriction and result in excessive inflammation in those with mild to moderate asthma.

Tahan et al. ${ }^{(13)}$ studied LXA4 in exercise induced asthma. They found that plasma levels of LXA4 after exercise were lower in children who had a positive bronchoconstriction response to exercise than those who had a negative response. They hypothesized that one of the mechanisms underlying airway hyperresponsiveness in patients with asthma who had a positive response to exercise may include the underproduction of LXs.

Fritscher et al. ${ }^{(\mathbf{1 4})}$ found that XA4 levels in mild asthmatics are no different than those in healthy controls while its levels is higher in moderate and severe asthmatics when compared with mild cases.

Regarding performance of blood lipoxin level in diagnosis of asthma, we found that the best cutoff value of blood lipovin A4 level in diagnosis of asthma was > 18.74 with area under curve 0.1 with sensitivity $63.6 \%$, specificity 63.3\%, PPV 63.6\%, NPV 63.6, +LR, -LR and accuracy $63.6 \%$.

While the best cutoff value in diagnosis of moderate asthma was $>33.24$ with area under curve 0.902 with sensitivity $100 \%$, specificity $79 \%$, PPV $100 \%$, NPV 46.2, +LR 4.85, -LR and accuracy $82.5 \%$.

Also we found that the best cutoff value of blood lipoxin A4 level in diagnosis of severe asthma was $>90.329$ with area under curve 1 with sensitivity $100 \%$, specificity $88.9 \%$, PPV 100\%, NPV 66.7, +LR 9, -LR 0 and accuracy $90.9 \%$. 
A study done by Kazani $\boldsymbol{e t}$ al. ${ }^{(15)}$ stated that A cutoff value of lipoxin provides $90 \%$ sensitivity and $92 \%$ specificity for the diagnosis of asthma (AUC $0.96, \mathrm{p}<0.001)$.

\section{CONCLUSION}

1. Serum lipoxin was significantly elevated in asthma patients when compared to controls.

2. Serum lipoxin levels in severe asthmatics were significantly higher than in moderate and mild asthmatics.

\section{REFERENCES:}

1. Global Initiative for Asthma (GINA Report) (2014): Global Strategy for Asthma Management and Prevention 2014 Revision. Available from http:// www.ginasthma. Org. Last updated August 2014.

2. Serhan C, Chiang N, Van Dyke T (2008): Resolving inflammation: Dual anti-inflammatory and proresolution lipid mediators. Nat Rev Immunol., 8:349361.

3. Barnig C, Levy B (2013): Lipoxin A4: A new direction in asthma therapy. Expert Rev Clin Immunol., 9(6): 491493.

4. Fukunaga K, Ichitani K, Taura $\mathbf{S}$ et al. (2005): Ribosomal DNA intergenic spacer sequence in foxtail millet, Setaria italica (L.) P. Beauv. and its characterization and application to typing of foxtail millet landraces. Hereditas., 142: 38-44.

5. Nafti S, Taright S, El Ftouh M et al. (2009): Prevalence of asthma in North Africa: the Asthma Insights and Reality in the Maghreb (AIRMAG) study. Respir Med., 103(2):2-11.

6. Simone F, Mustard C, Simons F et al. (2001): Socioeconomic status, drug insurance benefits, and new prescriptions for inhaled corticosteroids in schoolchildren with asthma. Arch Pediatr Adolesc Med., 155(11):1219-24.

7. Levy B, De Sanctis G, Devchand P et al. (2002). Multipronged inhibition of airway hyper-responsiveness and inflammation by lipoxin A4. Nat Med., 8:10181023.

8. Yin P, Wu S, Zhang Y et al. (2010): Reversed changes of the 15-lipoxygenase product lipoxin $\mathrm{A}_{4}$ and the 5lipoxygenase product leukotriene $\mathrm{C}_{4}$ in children with asthma. Pediatr pulmo., 45(4):333-340.

9. Rabie A, Mahmoud M, Moez $P$ et al. (2008): Assessment of lipoxin \& eotaxin as markers of severity in patients with bronchial asthma. Egypt J Chest Diseases and Tuberculosis, 57:1-14.

10. Bhavsar P, Levy B, Hew M et al. (2009): Corticosteroid suppression of lipoxin A4 and leukotriene B4from alveolar macrophages in severe. Respir Res., 11(1): 71-6.

11. Vachier I, Bonnans C, Chavis C et al. (2005): Severe asthma is associated with a loss of LXA4, an endogenous anti-inflammatory compound. J Allergy Clin Immunol., 115:55-60.

12. Levy B, Bonnans C, Silverman E et al. (2005): Severe Asthma Research Program, NHLBI. Diminished lipoxin biosynthesis in severe asthma. Am J Respir Crit Care Med., 172:824-830.

13. Tahan F, Saraymen R, Gumus H (2008): The role of lipoxin $\quad \mathrm{A}_{4}$ in exercise-induced bronchoconstriction in asthma. J Asthma, 45(2):161-164.

14. Fritscher L, Rodrigues M, Silverman F et al. (2012): Profile of eicosanoids in breath condensate in asthma and COPD. J Breath Res., 6(2):026001.

15. Kazani S, Planaguma A, Ono E et al. (2014): Exhaled Breath Condensate Eicosanoid Levels Associate with Asthma and its Severity. J Allergy Clin Immunol., 132(3): 547-553. 